\title{
Los caminos del Rionegro: historia del ferrocarril de Cundinamarca, 1847-1953
}

\author{
Oswaldo Escobar Muriel \\ Bogotá: Editorial Pontificia Universidad Javeriana \\ 2018. 356 p. \\ Leonor Eugenia Reyes Pavón \\ Licenciada en Historia, Maestra en Historia. El Colegio de Michoacán, Zamora de Hidalgo, \\ México. \\ $\square$ leonore@colmich.edu.mx \\ (1) ORCID: 0000-0002-6931-9883 \\ ڤn Google Scholar
}

Oswaldo Escobar Muriel es Ingeniero Civil e Historiador por la Universidad Javeriana, miembro de la Academia de Historia de Bogotá y de la Academia Colombiana de Historia de la Ingeniería y de las Obras Públicas. La obra que nos interesa reseñar es resultado de la combinación de estos dos campos en los que Escobar Muriel se ha desempeñado; desde mi punto de vista, allí radica su originalidad. Como el mismo autor lo menciona, su interés es estudiar la construcción del ferrocarril desde las implicaciones técnicas. Esta perspectiva resulta novedosa porque normalmente, cuando se estudian los caminos de hierro, los focos de atención son los impactos económicos y políticos, y en menor medida los efectos sociales. El libro se divide en nueve capítulos, en los que se abarca un periodo muy temprano que dio origen al Ferrocarril de Cundinamarca hasta su desaparición en 1953.

El primer capítulo inicia con una descripción de los caminos existentes en la zona, algunos de los cuales datan del periodo prehispánico, así como de la agreste situación geográfica local, lo cual complicaba la comunicación terrestre al tener que vadear ríos o subir y bajar cordilleras. Los peninsulares, ante la necesidad de extender sus dominios, construyeron otros senderos con la finalidad de agilizar el traslado; estas 
rutas históricas de transporte se conservaron hasta que comenzaron los primeros proyectos para la construcción de un ferrocarril. Escobar Muriel mencionaba que este fue resultado de las exploraciones realizadas por Antoine Poncet para la construcción de un camino entre Bogotá y un punto del río Magdalena. La Comisión Corográfica, encargada de elaborar la conformación geográfica de la República de la Nueva Granada, propuso un camino con la misma dirección, pero con un trazado diferente, e Indalecio Liévano, quien partiendo del trabajo realizado por los anteriores hizo varias propuestas de caminos para la región del Magdalena.

El autor señala que el Ferrocarril de la Sabana, y su posterior prolongación a Rionegro, sentó las bases de lo que sería el Ferrocarril de Cundinamarca. El segundo capítulo se aboca a estudiar la realización de ese proyecto que en sus orígenes reunió capital del Estado y de particulares, pero cuya realización quedó en manos de la Compañía del Ferrocarril de la Sabana, cuya fundación se realizó con ese propósito: encargarse de la construcción y administración de la vía. La vida de esta compañía resultó tormentosa debido a los frecuentes cambios administrativos que sufrió hasta 1916, la solución para subsanar los problemas que había sufrido durante un largo periodo fue transformarse en el Ferrocarril de Cundinamarca, aunque esto no resolvió los problemas existentes entre sus dos principales accionistas: el gobierno nacional y el departamento. Al final, estas problemáticas afectaron su administración, así como las ganancias que se obtuvieron de su explotación, además de que imposibilitaron la mejora y expansión de la vía hacia otros destinos.

En el siguiente capítulo, se utiliza como ejemplo lo acontecido con el ferrocarril a El Dintel, más tarde convertido en ramal, para mostrar que muchas de las decisiones que se tomaron con respecto a la construcción y modificaciones en las vías, no fueron el resultado de un proyecto estructurado, sino de una serie de decisiones que al parecer fueron tomadas sin realizar los estudios pertinentes y vinculadas a la influencia política que tenía quien los proponía.

La construcción del Ferrocarril de Cundinamarca estuvo plagada de problemas de todo tipo: administrativos, económicos, de proyección y ejecución, dada la falta de planeación al momento de ejecutar los trabajos. Estos dieron inicio desde dos frentes donde se evidenciaban sus respectivas divisiones, la primera abarcó desde Bogotá hasta Villeta, entendiendo que la vía hasta La Tribuna ya estaba construida, y la segunda iría desde Puerto Liévano hasta Villeta. Ante las dificultades presentadas por la compañía, en 1928 se tomó la decisión de contratar una empresa alemana para completar los trabajos de la segunda división. 
La Philipp Holzmann A.G. quedó encargada de terminar la vía entre el puerto y Cambras, así como de construir el resto del camino hasta unirlo con la primera división. La contratación de esta empresa fue completamente novedosa en cuanto a la construcción de ferrocarriles en Colombia y marcó un cambio en la manera en que se podían ejecutar grandes obras. En los capítulos cuatro y cinco se describen los trabajos realizados en ambas divisiones.

El capítulo sexto está dedicado a un aspecto que, si bien no era en sí mismo parte de la vía, fue factor de gran importancia: el puerto en el río Magdalena. Este fue uno de los motivos principales que impulsó la construcción del Ferrocarril de Cundinamarca: establecer la conexión entre ese punto y la capital, facilitando la entrada y transporte de mercancías entre ambos lugares. Por lo tanto, aquí encontramos información referente al establecimiento de un puerto en la zona, las propuestas, dificultades y negociaciones para lograr esa empresa.

En el siguiente capítulo el autor menciona varios temas, no necesariamente relacionados entre sí, vinculados al funcionamiento de la vía en varios aspectos. En un primer apartado, presenta los resultados de la explotación del ferrocarril, haciendo evidente que en la década de 1930, factores como la competencia con las compañías de camiones afectaron la rentabilidad de la vía. En el segundo, aborda muy brevemente los cambios realizados para la homogenización del ancho de la vía. El tercero está dedicado a la entrega de los trabajos realizados por la Holzmann. El cuarto aspecto es la explotación y los problemas presentados en el camino de hierro que requirieron la inversión del capital obtenido para subsanarlos. En un quinto, se nombran las estaciones existentes a lo largo de la vía, aunque no se profundiza en sus características, establecimiento, puesta en servicio u otros datos. El sexto, trata la competencia que representó el transporte carretero y la manera en que afectó de forma negativa el volumen de carga del ferrocarril, así como otros inconvenientes vinculados al déficit que presentaban las finanzas de la compañía y las alternativas que buscaron para mejorar los problemas económicos. En el último, se aborda la operación mediante la cual la vía quedó bajo la administración del Consejo Nacional de Ferrocarriles, los resultados obtenidos, la disolución de la sociedad en 1952 de acuerdo con el acta constitutiva de la empresa, y en 1960 la compra de los derechos que el departamento de Cundinamarca tenía sobre la vía por parte del gobierno nacional. 
En el octavo capítulo presenta un panorama de la actuación del gobierno en cuanto a la contratación de las obras, otorgando los permisos y concesiones, donde resulta evidente la falta de planeación, aunada a la inexperiencia por parte del gobierno colombiano para impulsar una red ferroviaria nacional. El resultado fue el surgimiento de proyectos desordenados que carecían de una estructura bien diseñada, además permitió que el constructor tuviese la capacidad de tomar prácticamente todas las decisiones con respecto a la obra. En este sentido, Escobar muestra que, antes de entrar al siglo XX, la contratación de obras casi siempre terminó siendo poco favorable para el gobierno.

A principios del siglo XX, se dio un cambio en la forma de concebir los medios de comunicación. La creación del Ministerio de Obras Públicas del Consejo Nacional de Vías de Comunicación y la Dirección Nacional de Ferrocarriles fueron resultado de un proyecto que buscó solucionar los problemas de transporte. El autor justifica la evolución en el otorgamiento de concesiones para realizar obras, con los cambios que surgieron durante ese periodo en Colombia (incluida la pérdida de Panamá) y la estructura de gobierno, que repercutieron en una mejor planeación en cuanto a la construcción de vías ferroviarias, al desarrollo de la ingeniería y a una bonanza económica en las arcas del Estado.

Finalmente, en el capítulo nueve, se profundiza en los motivos que llevaron a la desaparición del Ferrocarril de Cundinamarca cuando se encontraba ya en manos del gobierno colombiano. El autor considera diferentes niveles de los que parte su reflexión, comparando lo sucedido con los ferrocarriles colombianos y otros casos sudamericanos; en el plano nacional se destacó la falta de un plan por parte del gobierno y, finalmente, los componentes locales dentro del departamento de Cundinamarca.

De la misma manera, Escobar Muriel hace una síntesis de todos los factores y decisiones que influyeron en esta vía, desde sus orígenes hasta su desaparición, pasando por las cuestiones, técnicas económicas y administrativas que se fueron presentando a lo largo del libro. Mediante el análisis de los aspectos técnicos de la construcción de la vía, pudo darse cuenta de que el trazado defectuoso originó una serie de problemas que se fueron acumulando condenándola a su desaparición.

Los aspectos negativos de la obra no son muchos ni muy graves, las dificultades principales son las transiciones entre los diferentes capítulos porque se realizan abruptamente, pues se siente que los capítulos no han finalizado, y aunque se mantiene la relación entre ellos, pudo ser mejor ejecutada. Los capítulos siete y ocho se salen un poco de la propuesta y, 
aunque contienen información interesante, me parece que no se alinean con lo presentado en los seis primeros. Finalmente, la organización de los capítulos lleva a que se repitan, en más de una ocasión, ideas o hechos que han sido mencionados con anterioridad, aunque ninguno de estos detalles demerita el trabajo y la investigación que culminó en este libro.

Una de las grandes virtudes de esta obra es la cantidad y variedad de fuentes primarias utilizadas por Escobar, que le permitieron hacer una minuciosa reconstrucción de esta historia. También se agradece la inclusión de planos elaborados por el autor y tomados de los archivos, así como las imágenes (obtenidas en el Institut für Stadtgeschichte Frankfurt), que resultan especialmente útiles para quienes desconocemos la región, puesto que permiten visualizar con mayor claridad el espacio geográfico que le sirve como escenario. De la misma forma, las reflexiones finales contenidas en el capítulo nueve son muy interesantes y valdría la pena retomar la perspectiva propuesta, por lo que recomiendo su lectura a los estudiosos de los ferrocarriles en general y no solo a los interesados en el espacio colombiano.

A pesar de que el autor señala que se centra en los aspectos técnicos de la construcción, la realidad es que la cuestión política y administrativa está presente de forma constante en los capítulos. Esto no demerita el trabajo, al contrario, ayuda a explicar y entender el por qué de muchas de las decisiones que se tomaron con relación a los ferrocarriles, resultado de una pugna entre los poderes nacional y departamental, así como de los vaivenes políticos de cada periodo. Considero que, de forma exitosa, el autor prueba la importancia de los factores técnicos, especialmente el trazo de la vía, como elementos determinantes en el "éxito o fracaso" de la misma. 